Supporting Information for

Specific and Nonspecific Metal Ion-Nucleotide Interactions at Aqueous/Solid Interfaces Functionalized with Adenine, Thymine, Guanine, and Cytosine Oligomers

Joseph G. Holland, Jessica N. Malin, David S. Jordan, Esmeralda Morales, and Franz

$$
\text { M. Geiger* }
$$

Department of Chemistry and the International Institute for Nanotechnology, Northwestern University, 2145 Sheridan Road, Evanston, IL 60208 (USA) E-mail: geigerf@chem.northwestern.edu

\title{
Methods
}

Fused silica hemispheres were used as the substrates for functionalization with ssDNA (ISP Optics). Prior to DNA functionalization, each hemisphere was cleaned in the following manner. First, the lens was treated with NoChromix (Godax Laboratories) for $1 \mathrm{hr}$. The hemispheres were then rinsed with Millipore water (18.2 $\left.\mathrm{M}_{-}\right)$, and sonicated in methanol (VWR) for $10 \mathrm{~min}$. Next, the hemispheres were placed in an oven at $100^{\circ} \mathrm{C}$ for $30 \mathrm{~min}$. Lastly, the hemispheres underwent plasma cleaning (Harrick Plasma, Ithaca, NY) on the highest setting for 1 min each. The lenses were then functionalized with the ssDNA using our previously established method..$^{1-3}$ The $21-$ mer DNA sequences (Integrated DNA Technologies) used in theses experiments had the following sequences: $\left(\mathrm{A}_{15}+\mathrm{T}_{6}\right)$ : 5'-AAA AAA AAA AAA AAA TTT TTT /3AmMO/-3', $\left(\mathrm{C}_{15}+\mathrm{T}_{6}\right):$ 5'-CCC CCC CCC CCC CCC TTT TTT /3AmMO/-3', and $\left(\mathrm{T}_{15}+\mathrm{T}_{6}\right): 5^{\prime}-\mathrm{TTT}$ TTT TTT TTT TTT TTT TTT /3AmMO/-3'. The strands were covalently attached to the 
fused silica hemisphere via their $-3^{\prime}$ end through a peptide bond between the /3AmMO/ modification and an $\mathrm{N}$-hydroxysuccinimide linker, as described in our previous work..$^{1-3}$ Care was taken to ensure that the substrates were not reacted with the DNA any sooner than $15 \mathrm{hrs}$ before their experimental use.

All of the solutions used in these experiments were prepared with Millipore water and maintained at $\mathrm{pH} 7.0 \pm 0.2$ by addition of dilute $\mathrm{HCl}$ (E.M.D., ACS grade) and $\mathrm{NaOH}$ (Sigma-Aldrich, 99.99\%). The aqueous $\mathrm{Mg}^{2+}$ solutions used in all adsorption experiments were made from $\mathrm{MgCl}_{2}\left(\mathrm{H}_{2} \mathrm{O}\right)_{6}$ (Sigma-Aldrich), and the background electrolyte solutions were prepared using $\mathrm{NaCl}$ (VWR 99\%). All pH measurements were performed with a Thermo Fisher Scientific $\mathrm{pH}$ meter that was calibrated on a daily basis, and all $\mathrm{Mg}^{2+}$ bulk concentrations were quantified using inductively coupled plasma atomic emission spectroscopy (ICP-AES, Varian).

An advanced schematic of our setup and the laser can be found in previously published work ${ }^{4-7}$ Briefly, the SHG experiments described here were performed with a regeneratively amplified Ti:sapphire laser (Hurricane, Spectra Physics, 120 fs pulse) that pumps an optical parametric amplifier (OPA-CF, Spectra Physics, $1 \mathrm{kHz}$ repetition rate) tuned to a fundamental wavelength of $650 \pm 5 \mathrm{~nm}$, far away from any bulk or surface electronic transition of DNA or the aqueous magnesium. ${ }^{1,8}$ The power of the input beam was then attenuated to $0.5 \pm 0.05 \mu \mathrm{J}$ using a variable density filter. The fundamental beam was directed through a half-wave plate that selected $p$-polarized light and that light was focused onto the ssDNA functionalized hemisphere/water interface at an angle just less than that of total internal reflection. The reflected beam, $\omega(650 \mathrm{~nm})$, was then removed by means of a UV-grade Schott filter, while the generated beam, $2 \omega(325 \mathrm{~nm})$, 
was directed into a monochromator set at $2 \omega$, and then into a Hamamatsu PMT. The intensity of the SH was then quantified through the use of a gated, single photon counting system. Prior to each experiment, both the SHG quadratic power dependence and the SHG bandwidth were verified. Adsorption experiments were performed at a flow rate of $\sim 1 \mathrm{~mL} / \mathrm{sec}$, which was controlled using peristaltic pumps and verified with a flow meter. Two separate reservoirs contained the aqueous solutions used in these experiments. The first solution contained a given $\mathrm{NaCl}$ background solution, while the second solution contained both the same concentration of $\mathrm{NaCl}$ plus the $\mathrm{Mg}^{2+}$ concentration of interest.

\section{Sensitivity Analysis}

In order to test the robustness of our fitting equation, a sensitivity analysis was performed on the SHG Gouy-Chapman fitting equation (General Text Eq. 1). This analysis was carried out by taking the partial derivative of the fitting equation with respect to A, B, $\mathrm{K}_{\mathrm{obs}},-0$, and ${ }_{-\mathrm{m}}$. These derivatives were then plotted respectively as a function of $\mathrm{A}, \mathrm{B}$, $\mathrm{K}_{\mathrm{obs}},{ }_{-0}$, and ${ }_{-\mathrm{m}}$ in Figure S1, S2, S3, S4, and S5 of the Supporting Information. In all sensitivity analyses the input parameters of: $\mathrm{B}=-0.32,{ }_{-0}=-0.016 \mathrm{C} / \mathrm{m}^{2},{ }_{-\mathrm{m}}=0.005 \mathrm{C} / \mathrm{m}^{2}$, $K_{\text {obs }}=10,000 \mathrm{M}^{-1},[\mathrm{M}]=1 \times 10^{-3} \mathrm{M}, \mathrm{C}_{\text {elec }}=0.01 \mathrm{M}$; were used as needed. 


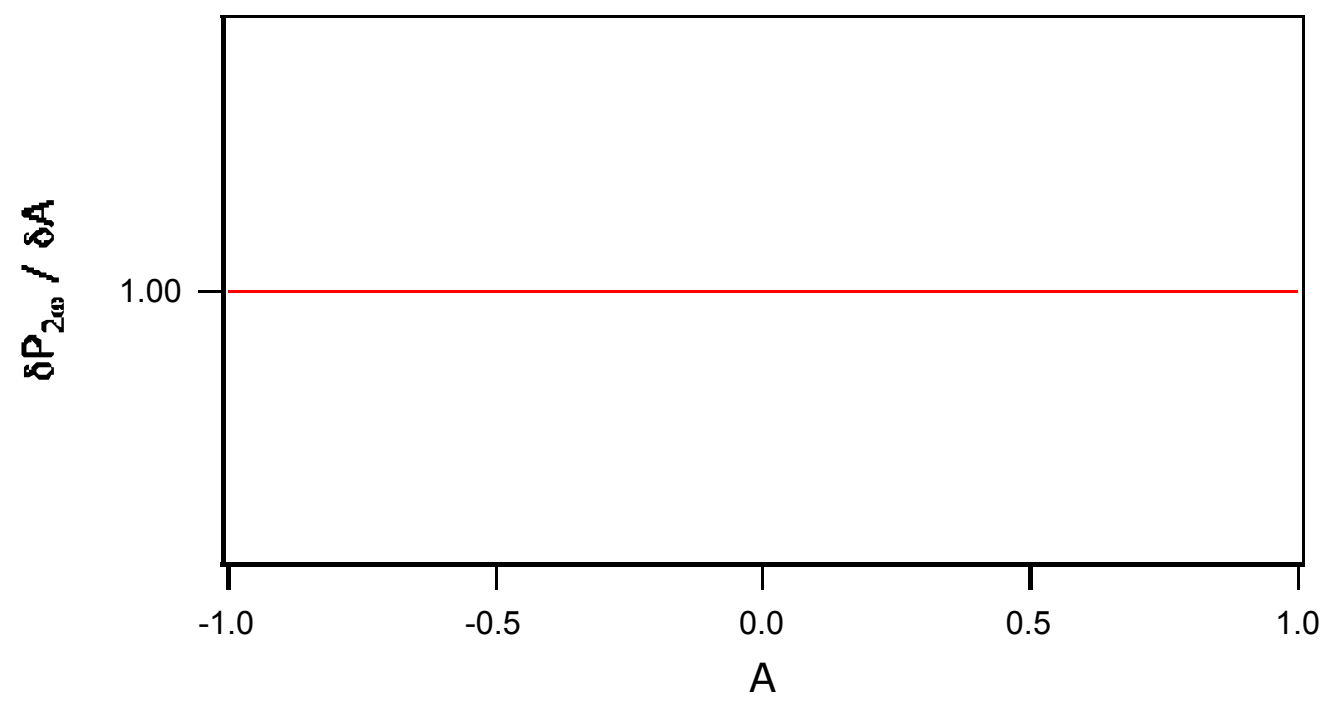

Figure S1. Sensitivity analysis for the fitting parameter A.

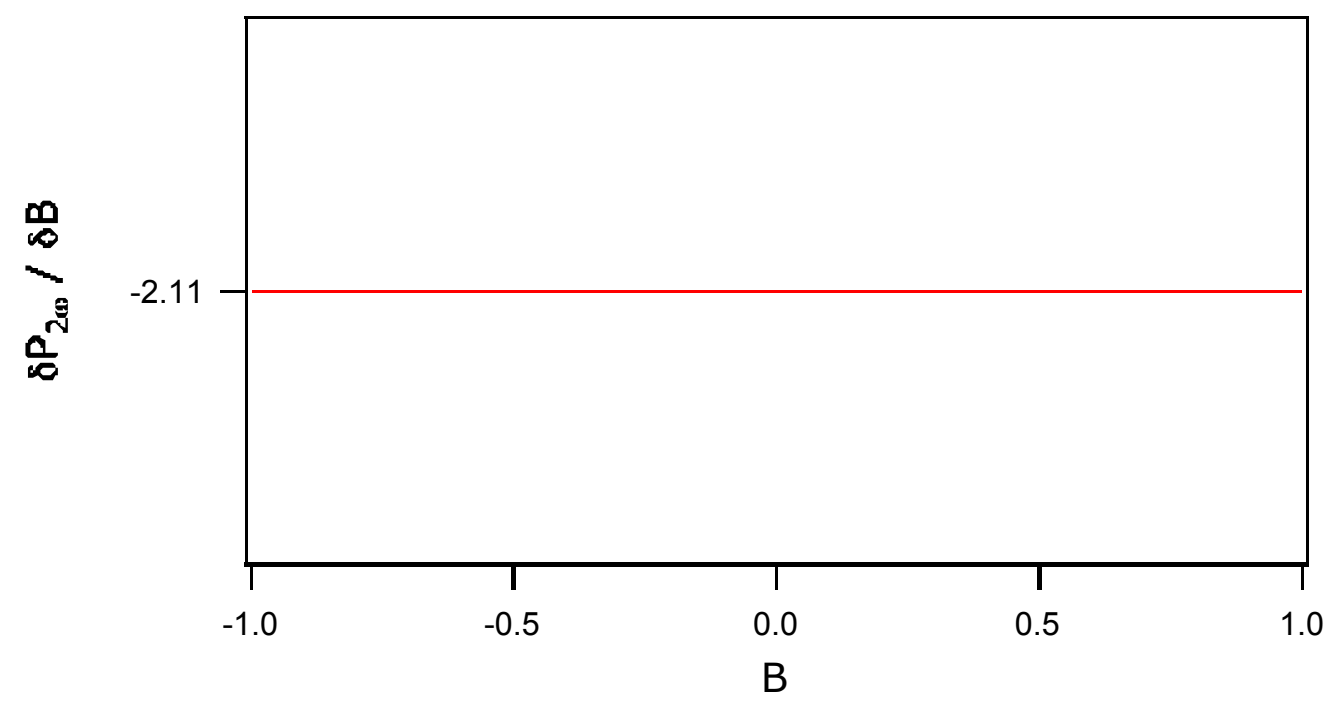

Figure S2. Sensitivity analysis for the fitting parameter B. 


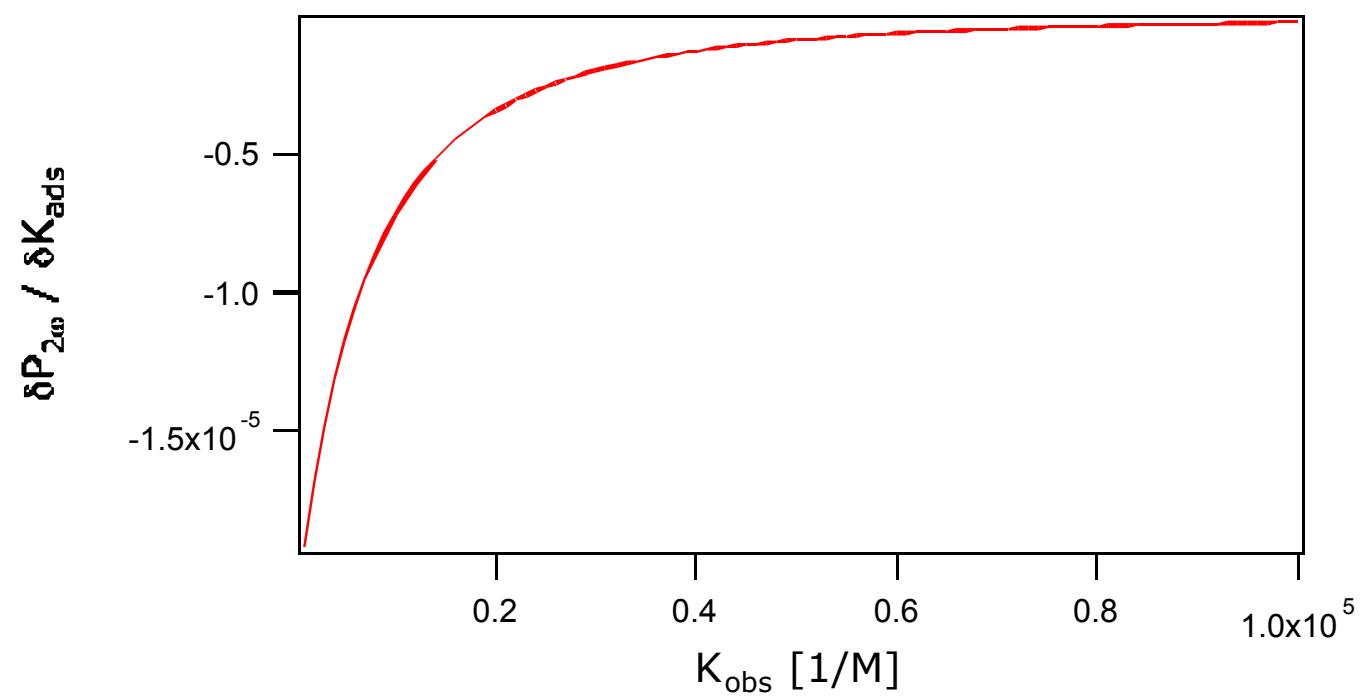

Figure S3. Sensitivity analysis for the observed binding constant, $\mathrm{K}_{\mathrm{obs}}$.

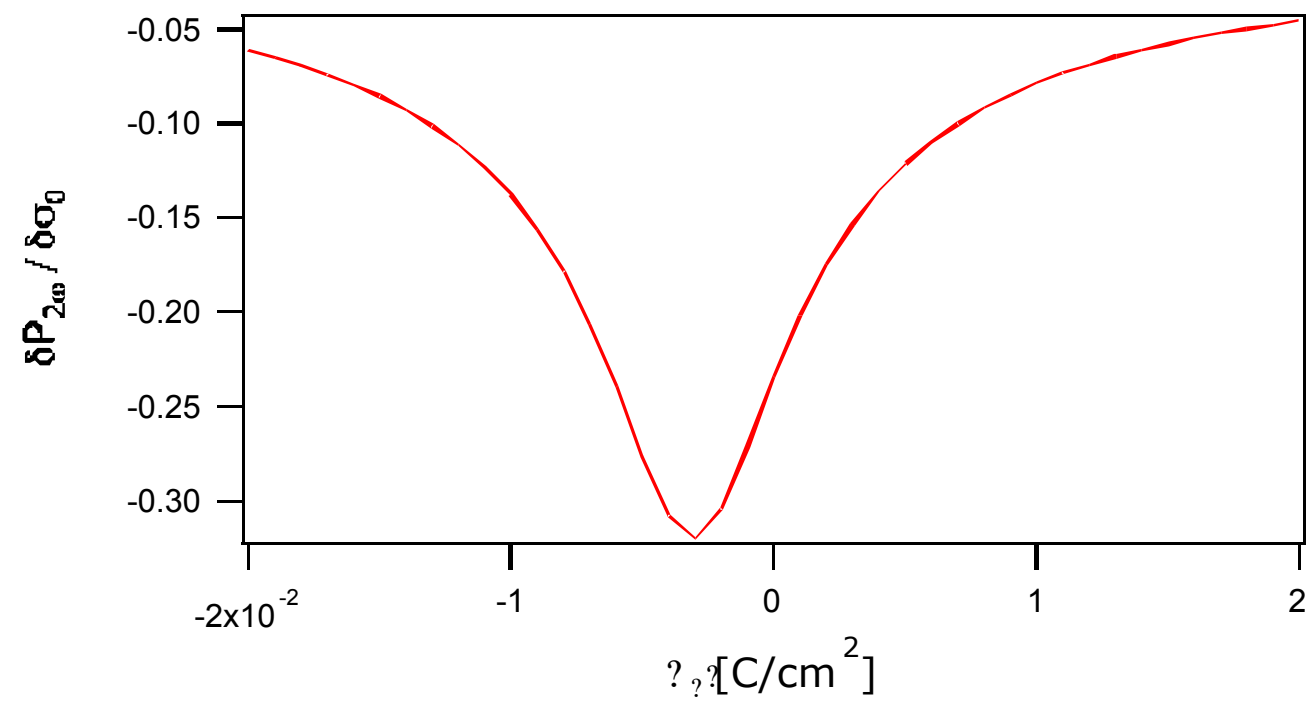

Figure S4. Sensitivity analysis for the initial surface charge density, ${ }_{-0}$. 


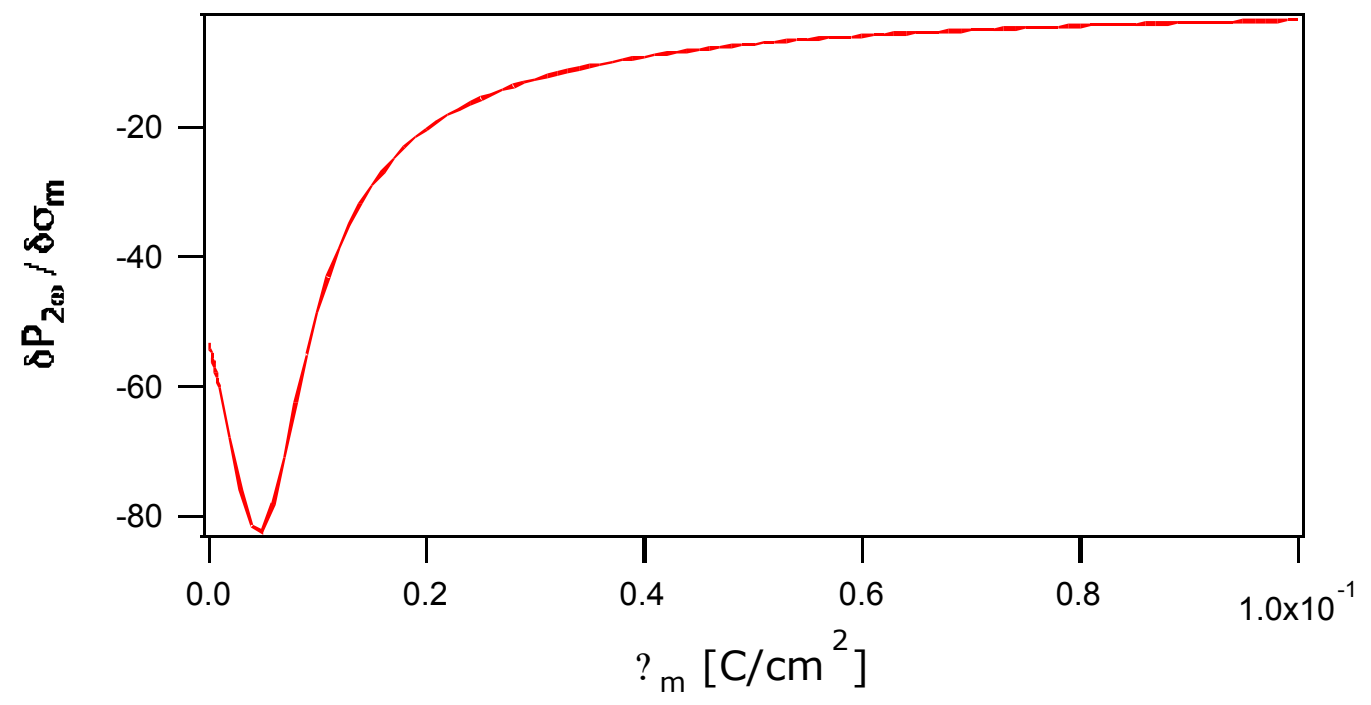

Figure S5. Sensitivity analysis for the maximum surface charge density, $-\mathrm{m}$.

\section{Adsorption Isotherms}

All of the SHG adsorption isotherms for the data presented in this work are shown here (Figures S6-S10). 


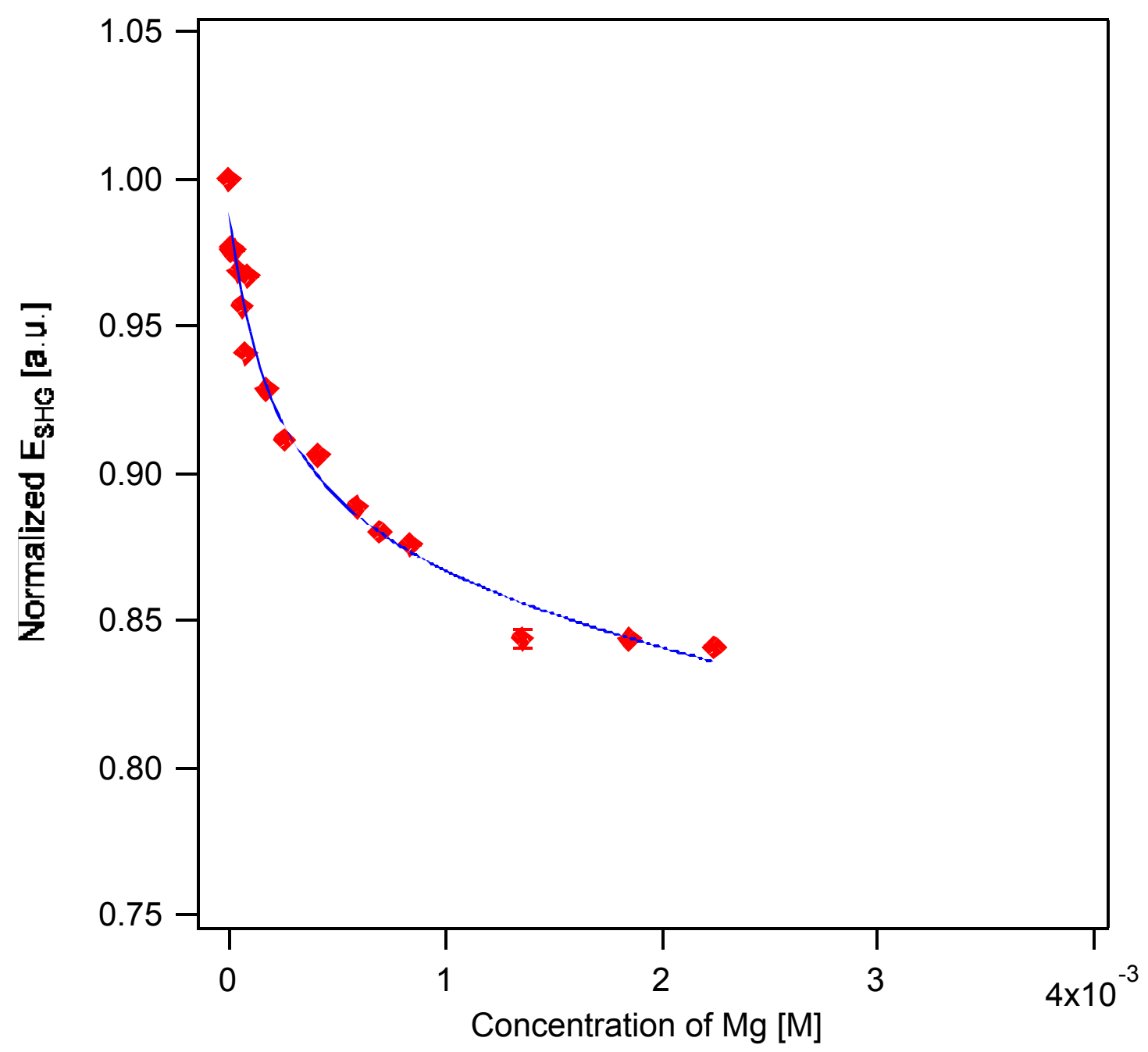

Figure S6. Adsorption isotherm for $\mathrm{Mg}^{2+}$ binding to the $\mathrm{A}_{21}$ functionalized silica interface at $\mathrm{pH} 7$, in the presence of $10 \mathrm{mM} \mathrm{NaCl}$. 


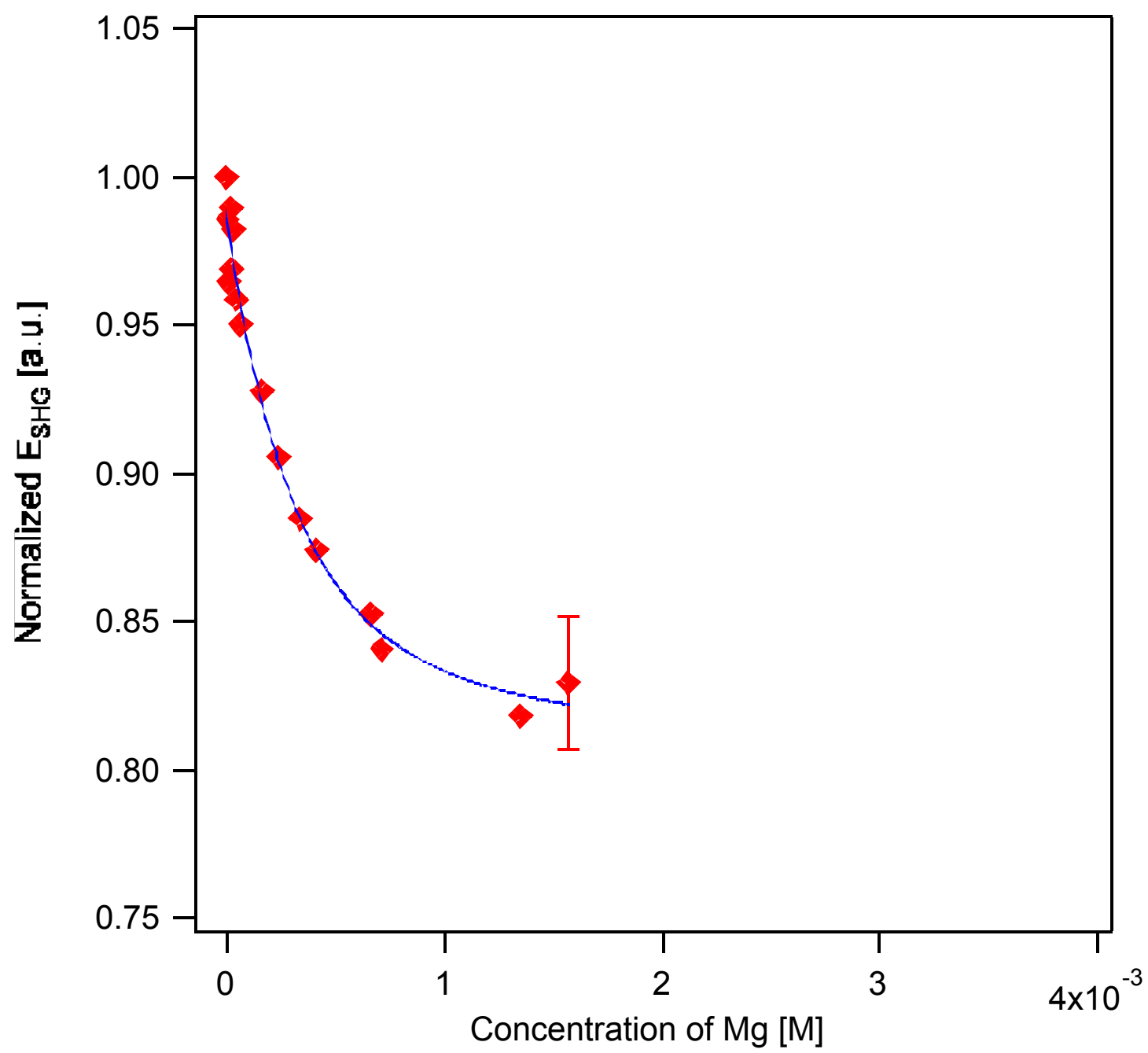

Figure S7. Adsorption isotherm for $\mathrm{Mg}^{2+}$ binding to the $\mathrm{C}_{21}$ functionalized silica interface at $\mathrm{pH} 7$, in the presence of $10 \mathrm{mM} \mathrm{NaCl}$. 


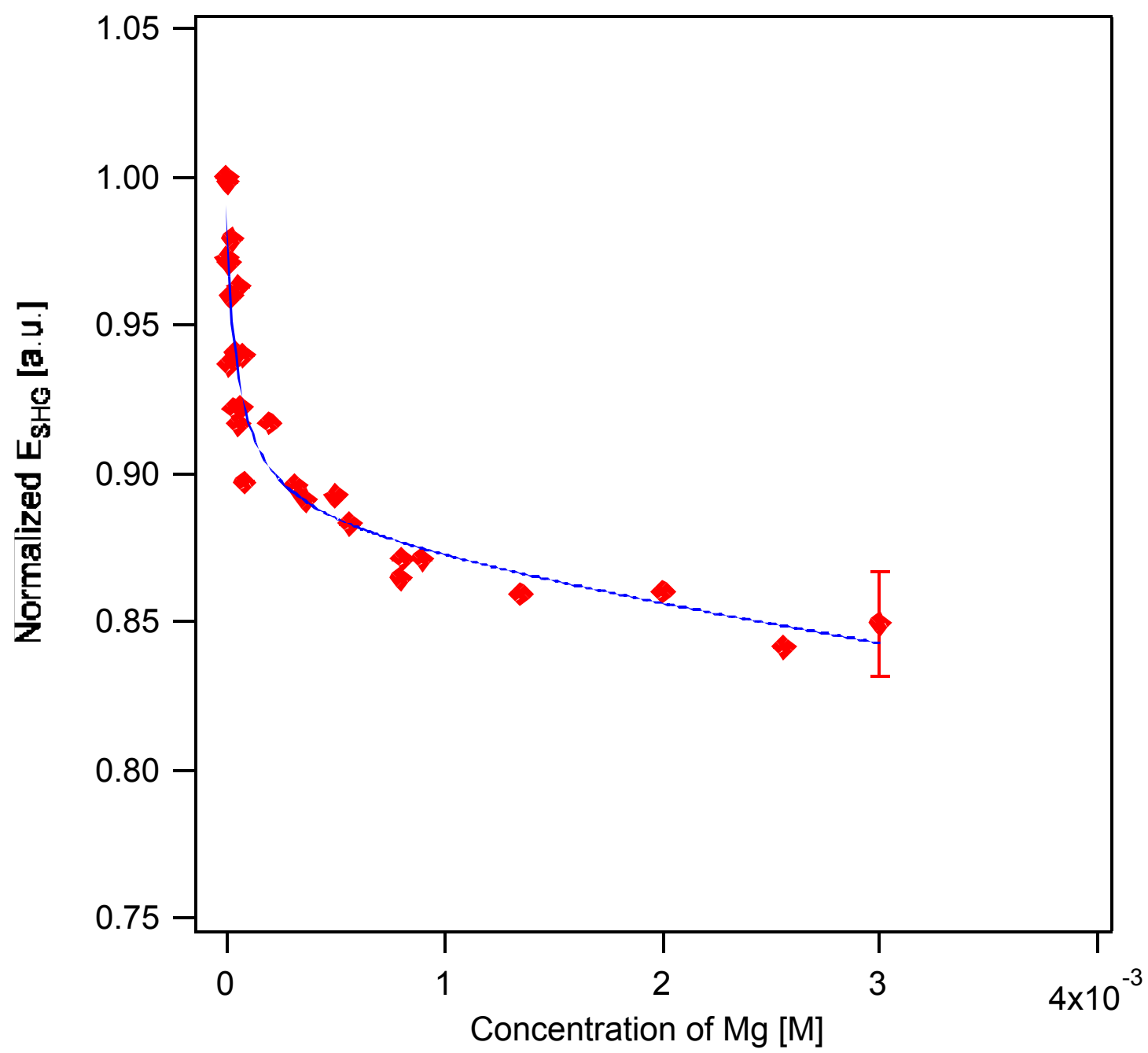

Figure S8. Adsorption isotherm for $\mathrm{Mg}^{2+}$ binding to the $\mathrm{T}_{21}$ functionalized silica interface at $\mathrm{pH} 7$, in the presence of $10 \mathrm{mM} \mathrm{NaCl}$. 


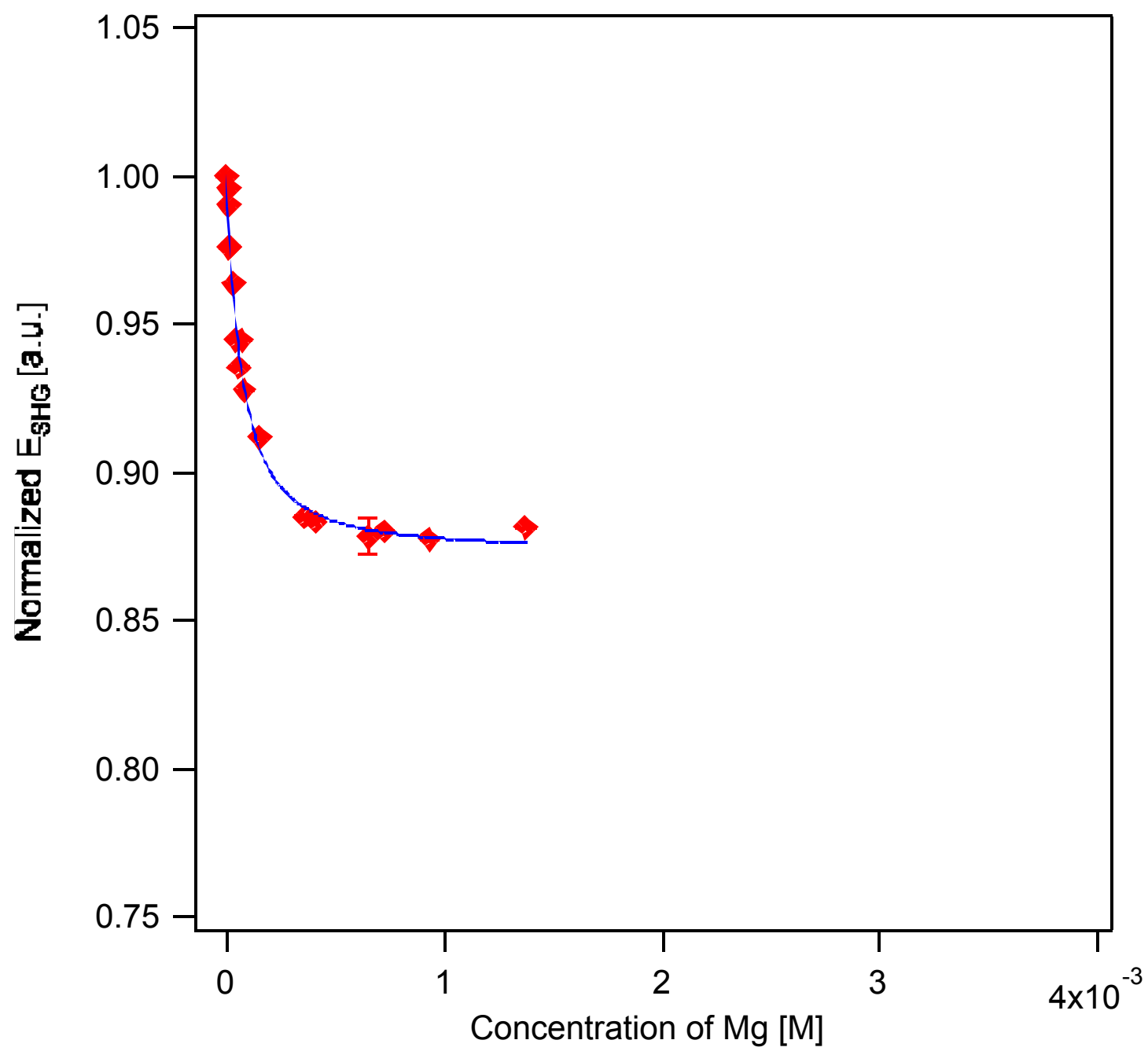

Figure S9. Adsorption isotherm for $\mathrm{Mg}^{2+}$ binding to the $\mathrm{G}_{21}$ functionalized silica interface at $\mathrm{pH} 7$, in the presence of $10 \mathrm{mM} \mathrm{NaCl}$. 


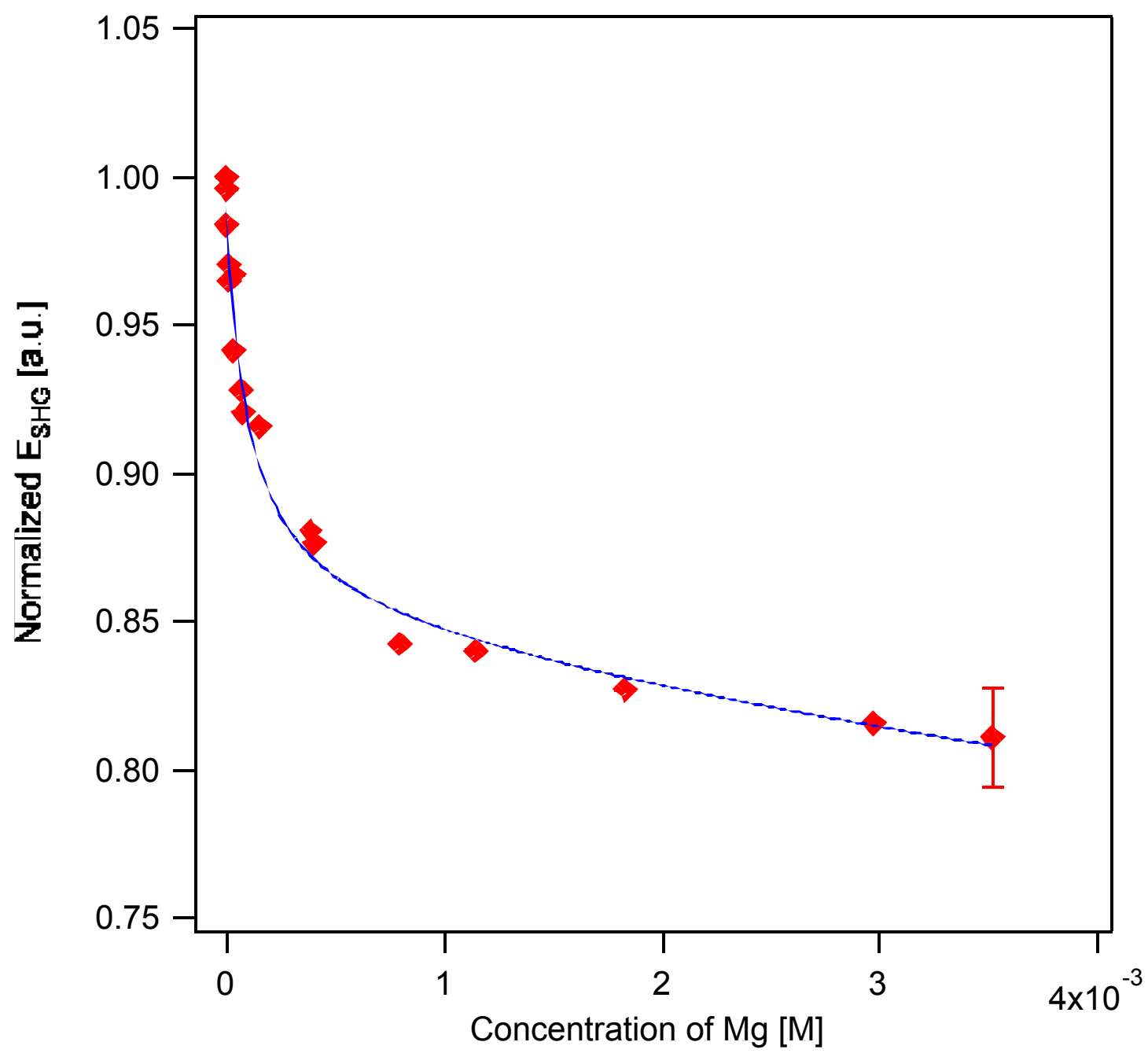

Figure S10. Adsorption isotherm for $\mathrm{Mg}^{2+}$ binding to the $\mathrm{C}_{15} \mathrm{~T}_{6}$ functionalized silica interface at $\mathrm{pH} 7$, in the presence of $10 \mathrm{mM} \mathrm{NaCl}$. 


\section{Additional Method Fit Results}

(Please reference paragraph 2 of Results)

\begin{tabular}{ccccccc} 
& $\mathbf{A}_{\mathbf{2 1}}$ & $\mathbf{C}_{\mathbf{2 1}}$ & $\mathbf{T}_{\mathbf{2 1}}$ & $\mathbf{G}_{\mathbf{2 0}}$ & $\mathbf{A}_{\mathbf{1 5}} \mathbf{T}_{\mathbf{6}}$ & $\mathbf{C}_{\mathbf{1 5}} \mathbf{T}_{\mathbf{6}}$ \\
\cline { 2 - 5 } $\mathbf{K}_{\text {bind }}\left[\mathbf{M}^{-1}\right]$ & $5(2) \times 10^{3}$ & $8(2) \times 10^{3}$ & $22(9) \times 10^{3}$ & $36(5) \times 10^{3}$ & $6(1) \times 10^{3}$ & $12(3) \times 10^{3}$ \\
& $6(1) \times 10^{3}$ & $10(3) \times 10^{3}$ & $10(20) \times 10^{3}$ & $80(20) \times 10^{3}$ & $7(2) \times 10^{3}$ & $9(3) \times 10^{3}$ \\
$-\Delta \mathbf{G}_{\text {bind }}$ & $31(1)$ & $32.2(7)$ & $35(1)$ & $35.9(4)$ & $31.9(4)$ & $33.2(7)$ \\
{$[\mathbf{k J} / \mathbf{m o l}]$} & $31.5(5)$ & $32.8(8)$ & $32.8(6)$ & $38(1)$ & $31.9(8)$ & $33(1)$ \\
$\begin{array}{c}\text { lon Density } \\
{\left[\mathbf{M g}^{\mathbf{2 +}}\right.}\end{array}$ & $3(2)$ & $11(2)$ & $3(1)$ & $11(2)$ & $7(1)$ & $4(1)$ \\
ions/strand] & $11(1)$ & $11(1)$ & $9(4)$ & $11(1)$ & $10(1)$ & $10(1)$ \\
$-\Delta \mathbf{G}_{\text {total }}$ & $90(60)$ & $350(70)$ & $110(40)$ & $400(70)$ & $220(30)$ & $130(30)$ \\
{$[\mathbf{k J} / \mathbf{m o l}]$} & $350(30)$ & $360(70)$ & $300(100)$ & $420(80)$ & $320(30)$ & $330(30)$
\end{tabular}

Table S1. Binding constants, free energies, ion number densities, and total free binding energies for $\mathrm{Mg}^{2+}$ interacting with fused silica/water interfaces functionalized with single stranded 21 -mers at $298 \mathrm{~K}, \mathrm{pH} 7$, and $10 \mathrm{mM} \mathrm{NaCl}$ concentration. The top value in each cell was calculated using by assuming that the screening electrolyte is monovalent (1:1). For this scenario, $\mathrm{C}_{\text {elec }}$ is expressed as the sum of both the background $\mathrm{Na}^{+}$concentration $(0.01 \mathrm{M})$ and the $\mathrm{Mg}^{2+}$ concentration. The bottom value in each cell was calculated by assuming the screening electrolyte to be divalent $(2: 2)$ and thus $\mathrm{C}_{\text {elec }}$ was expressed solely as the $\mathrm{Mg}^{2+}$ concentration. Free energies were obtained after referencing to the 55.5 molarity of water.

1. Boman, F. C.; Gibbs-Davis, J. M.; Heckman, L. M.; Stepp, B. R.; Nguyen, S. T.; Geiger, F. M., Journal of the American Chemical Society 2009, 131, (2), 844-848.

2. Boman, F. C.; Musorrafiti, M. J.; Gibbs, J. M.; Stepp, B. R.; Salazar, A. M.; Nguyen, S. T.; Geiger, F. M., Journal of the American Chemical Society 2005, 127, (44), 15368-15369.

3. Stokes, G. Y.; Gibbs-Davis, J. M.; Boman, F. C.; Stepp, B. R.; Condie, A. G.; Nguyen, S. T.; Geiger, F. M., Journal of the American Chemical Society 2007, 129, (24), 7492-7493.

4. $\quad$ Mifflin, A. L.; Musorrafiti, M. J.; Konek, C. T.; Geiger, F. M., The Journal of Physical Chemistry B 2005, 109, (51), 24386-24390.

5. Hayes, P. L.; Gibbs-Davis, J. M.; Musorrafiti, M. J.; Mifflin, A. L.; Scheidt, K. A.; Geiger, F. M., Journal of Physical Chemistry C 2007, 111, (25), 8796-8804.

6. Hayes, P. L.; Malin, J. N.; Konek, C. T.; Geiger, F. M., Journal of Physical Chemistry A 2008, 112, (4), 660-668.

7. Malin, J. N.; Hayes, P. L.; Geiger, F. M., Journal of Physical Chemistry C 2009, 113, (6), 2041-2052. 
$\mathrm{S} 13$

8. Tonzani, S.; Schatz, G. C., Journal of the American Chemical Society 2008, 130, (24), 7607-7612. 